KLEINE TEXTE FÜR VORLESUNGEN UND ÜBUNGEN HERAUSGEGEBEN VON HANS LIETZMANN 138

\title{
CRATIPPI HELLENICORUM FRAGMENTA OXYRHYNCHIA
}

\author{
SCHOLARUM IN USUM EDIDIT
}

JUSTUS HERMANNUS LIPSIUS

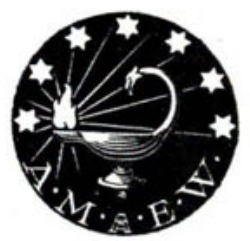

BONN

A. MARCUS' UND E. WEBER'S VERLAG I9 16 